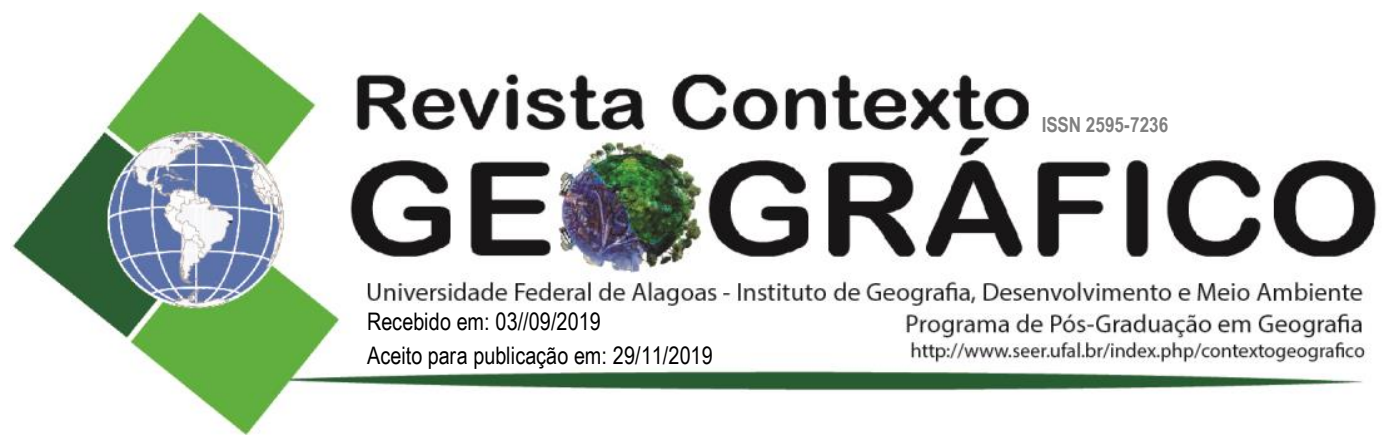

\title{
A PAISAGEM NA GEOGRAFIA
}

\author{
Joseline da Silva Alves \\ Mestranda do Programa de Pós-graduação em Geografia-PPGG/UFPB, AL, Brasil \\ joseline.geo@gmail.com \\ Camila Cunico \\ Professora Doutora do Departamento de Geociencias/UFPB, AL, Brasil \\ camilacunico@yahoo.com.br
}

Jonas Otaviano Praça de Souza

Professor Doutor do Departamento de Geociencias/UFPB, AL, Brasil

jonasgeoufpe@yahoo.com.br

\begin{abstract}
RESUMO - Desde a Antiguidade, não ainda com essa denominação, a Geografia foi conceituada como uma das responsáveis pela criação de uma imagem do mundo e por sua descrição. O presente trabalho tem por objetivo fazer um breve resgate da história da Geografia bem como seus conceitos de análise contribuíram para sua estruturação do seu objeto de estudo, tendo a paisagem como sendo aquela que se define como o resultado visível dos processos que agiram/agem para constituir o espaço geográfico. A paisagem como categoria de análise contribui para o entendimento dos processos que atuaram e/ou atuam para definir determinada configuração espacial, necessário para pensar em uma maneira de otimizar o uso dos recursos e assim buscar a qualidade socioambiental
\end{abstract}

Palavras-chave: História da Geografia; Qualidade socioambiental; Unidades de Paisagem.

\section{THE LANDSCAPE IN GEOGRAPHY}

\begin{abstract}
Since the antiquity, even without that denomination, the geography was dignified as one of the responsible to create an image of the world and his description. The present work has as main goal, bring a rescue of the Geography history and how his analysis concepts contributed to the geography structure of his object of study, aiming the landscape as the one of is defined as the visible result of the process that operated/operate to build the geographic space. The landscape as category of analysis, contributes to the meaning of the process that acted and/or act to define such spatial settings, necessary to mind (think) in a way to optimize the resources uses and aim the socioenvironmental quality.
\end{abstract}

Keywords: Socioenvironmental quality; Landscape Units.

\section{INTRODUÇÃO}

A ciência é uma forma de conhecimento de grande destaque na sociedade contemporânea, que se distingue das outras de saber, como por exemplo, o senso comum, pela sua sistematização e criticidade fazendo com que se torne referência em tomada de decisões considerando que a ciência se tornou uma maneira de enxergar a realidade (DEMO, 1995). 
Khun (1970) identifica a ciência como a atividade que visa responder a problemas guiando-se por pressupostos para explicar determinados fenômenos. No entanto, com a evolução das sociedades e do avanço tecnológico, surgem as chamadas anomalias que levam as ciências a buscar uma nova forma de compreender tal fenômeno, de modo que a ela deve está em processo de aperfeiçoamento.

De acordo com Khun (1970) e Japiassu, (1991) ao analisar determinada teoria ou obra deve-se considerar o contexto no qual esta estava inserida, pois isso contribui demasiadamente no entendimento do processo de sua construção, não estando a ciência totalmente isolada das influencias advindas do senso comum, nem tão pouco de ideologias. As ciências e seus conceitos são elaborados por homens, homens esses que são produtos da sociedade e dessa maneira, acabam por colocar em suas obras um pouco de si e de sua visão de mundo

A Geografia, enquanto ciência surge com a perspectiva de buscar compreender como estar espacializado os fenômenos sobre a superfície e desse modo entender como esses repercutem no modo de ocupação dos agrupamentos humanos (VITTE, 2015).

Atualmente, entende-se que Geografia busca compreender o espaço geográfico e que esse é constituído a partir da interação (totalidade) dos seus elementos. Através das suas categorias de análise, que em conjunto definem o objeto de estudo que possuem o papel de ajudar a ler/conhecer o espaço geográfico (SANTOS, 2014, CASTRO, 2000).

O presente trabalho tem por objetivo fazer um breve resgate da história da Geografia bem como seus conceitos de análise contribuíram para sua estruturação do seu objeto de estudo, tendo a paisagem como sendo aquela que se define como o resultado visível dos processos que agiram/agem para constituir o espaço geográfico.

\section{A CIÊNCIA GEOGRÁFICA}

O conhecimento geográfico tem sua origem no senso comum com um caráter empírico, no qual o homem, através da sua ação direta sobre o meio, no decorrer do tempo acabou por diversificar sua prática provocando um acúmulo de conhecimentos espaciais, e isso conduziu a um nível cada vez maior de abstração e sistematização desse saber geográfico, ao ponto que se transformou esse saber em ciência que se conhece atualmente por Geografia (MOREIRA, 2012).

Moreira (2015) afirma que a Geografia permaneceu atrelada durante bastante tempo as características e diferenciações da superfície terrestre. A geografia praticada era pautada no conjunto de conhecimentos empíricos voltados para a classificação do mundo físico, ou seja, o papel da geografia era representar a superfície terrestre por meio da identificação da heterogeneidade e diversidade de suas formas naturais e desse modo buscar compreender a sua organização.

Com Ritter e Humbolt a Geografia passa por uma transformação, ao sair do seu papel taxonômico e descritivo e assumindo a condição de ciência ao apresentarem métodos e teorias que auxiliam na compreensão determinados fatos geográficos (VITTE, 2007b).

Ritter, baseado na corologia, parte da ideia que os fenômenos espaciais possuem uma organização, que ao serem identificadas e delimitadas, poderiam ser comparadas (método comparativo), formando um mosaico de paisagens. Humbolt, por sua vez, propõe uma visão holística da natureza (Geografia das Plantas) no qual o orgânico, o inorgânico e o homem relacionam-se constantemente de forma que a interação entre esses fatores leva-os a se organizar de modo a apresentar padrões que se expressam na superfície de maneira que se pode estabelecer certa zonalidade, isto é unidades de natureza ou de paisagens que são refletidas principalmente nas formações vegetais (MOREIRA, 2015; 2012). 
Contudo, com o advento do Positivismo procurou-se cada vez a especialização do conhecimento e que levou a institucionalização das ciências, bem como a definição de limites entre elas. No positivismo eram valorizados a observação e os experimentos como forma de obtenção do conhecimento, sendo assim, as ciências naturais acabaram por ter mais destaque por apresentam um método de pesquisa que se pautava em experimentos, ao contrário das ciências humanas que ainda estavam em processo de desenvolvimento, considerando que não possuem uma base metodológica definida (VITTE, 2007a).

De acordo com Moreira (2015) e Claval (2014) a institucionalização da Geografia ocorre no período da predominância das teorias Positivistas, no ficou conhecido como Geografia Clássica, logo os estudos geográficos davam ênfase aos estudos no campo da chamada Geografia Física, que primava pela busca do conhecimento do funcionamento da natureza, com o propósito de dominação dos recursos naturais, pautados na relação homem-natureza.

Dentro da Geografia Clássica destacam-se a alemã, que tem precursor Ratzel no qual baseava-se na ideia de dependência dos povos ao solo (base física), apresentando conceitos, como território e espaço vital de grande importância para a compreensão da interação homem-meio, e como essa relação repercute no espaço-tempo (RATZEL, 1986; CLAVAL, 2014).

De acordo com Ratzel (1986, p. 93) o território é concreto e que quando somado com as relações sociais e de produção é que se torna possível a existência do espaço geográfico, sendo delimitado de estado “(...) o Estado não existir sem um solo”, isto é, sem esta base sólida não é possível a existência do Estado visto que todas as atividades humanas, independentemente das quais sejam, estão assentadas sobre um solo que por sua vez encontram-se relacionadas a uma dinâmica política.

O solo, de acordo com Ratzel (1986) torna-se essencial para as sociedades vista não apenas com a base física sobre a qual se constituem, mas também onde elas retiram os recursos necessários para a sua existência e manutenção, influenciando na sua estrutura e organização político-social. Ratzel (1986) afirma ainda que não se pode entender a configuração espacial se não são levados em consideração os processos de sua formação que ocorrem pela interação entre a sociedade e a natureza, sendo que o resultado desta é representado na paisagem.

Desse modo, Ratzel defende que a manutenção e expansão de território se dão através do conhecimento dos seus elementos físicos com a perspectiva de uso dos recursos naturais, de modo que aos povos ditos "primitivos" as condições naturais acabam, por vezes, impondo limites ao seu desenvolvimento, o que levou a escola alemã a ficar conhecida como Determinista (CLAVAL, 2014).

A Geografia clássica francesa, de acordo com Claval (2014) apresenta uma perspectiva diferenciada da escola alemã, no qual as questões humanas aparecem de maneira mais atuante sobre os espaços. Para o autor, a geografia francesa que tem como nome principal Vidal de La Blache, os homens utilizam e viam os recursos naturais de maneiras diferenciadas e que essa forma de ver e se relacionar estava condicionada ao seu gênero de vida, que pode ser conceituado como "ação metódica e contínua, que age fortemente sobre a natureza ou, para falar como geógrafo, sobre a fisionomia das áreas” (LA BLACHE, 1991, p. 114).

Os gêneros de vida refletem o modo como a sociedade compreende e interfere no ambiente no qual está inserido, o que pode provocar alterações nesses espaços. Contudo, La Blache (1911) atenta para o fato da natureza possuir a capacidade de retornar ao seu estado inicial de equilíbrio, mesmo com os avanços tecnológicos criados pelo homem que lhe permite um maior poder de intervenção, ele ainda pode ficar submetido as intempéries naturais.

Logo, o que se percebe que na perspectiva de La Blache o homem faz uso dos bens naturais de acordo com as possibilidades que lhe foram ofertadas, não estando condicionadas a ela. Esse modo de ver a relação entre a sociedade e a natureza de La Blache e seus discípulos a levou a 
ficar conhecida como escola Possibilista.

Para La Blache (1911) a forma como a sociedade se constitui e se organiza dita o modo como será apropriado os recursos naturais, sendo assim, a inserção de novos hábitos muda também a maneira de enxergar e de fazer uso da natureza, na qual as alterações que ocorrem sobre o meio por intermédio da ação humana estão relacionadas com o desenvolvimento da sociedade como também do melhoramento da técnica, dando origem a um mosaico de paisagens.

As paisagens seriam, portanto, a fisionomia de uma área e que acaba por refletir toda uma dinâmica social que ali se pratica, sendo resultado das interações homem-homem/homemnatureza. As paisagens diferem uma das outras por possuírem dinâmicas próprias que também estão condicionas ao modo que a ação humana acontece sobre ela. O papel do geógrafo seria estudar como as paisagens se distribuem sobre a superfície da terra, isto é, reconhecer a diferenciação de áreas.

Claval (2014) chama a atenção para o fato de apesar de a geografia francesa levar em consideração que ação humana não esta totalmente submetida às condições naturais, mas reconhece o seu papel limitador em determinadas casos. Atenta também para o interesse da escola Possibilista ao defender, de forma bastante sutil, a superioridade de determinadas culturas como uma maneira de justificar uma possível dominação, fato que também é notável nos trabalhos da escola alemã. (CLAVAL 2014; CAMPOS, 2014).

Logo o que se percebe que em ambas as escolas, apesar dos trabalhos versarem no conhecimento dos bens naturais, pautados na relação que os grupos humanos têm com o meio, como uma forma de garantir a expansão e/ou dominação de novos/outros territórios. (CALVAL, 2014).

A Geografia na percepção de Hartshorne (1978) nasce do interesse, da inquietude do homem em conhecer lugares, saber seu dinamismo. Consiste em buscar compreender o caráter variável das áreas em termos de todos os aspectos relacionados que constituem em sua expressão de conjunto, exatamente esse caráter variado. Para isso o autor utiliza a comparação como metodologia, dando origem ao método regional, que se pauta em identificar áreas homogêneas que se diferenciam do seu entorno.

Hartshorne (1978) afirma que não se deve buscar as diferenças, mas sim, tentar compreender as variações dos fenômenos espaciais e que a ação humana dentro desse contexto não aparece como inerte, mas que também atua de forma direta de modo a modificar e criar relações funcionais. Contudo, na visão do autor, não se deve tentar fazer distinção entre os fatores ditos humanos e naturais, pois eles acontecem de forma integrada, resultando nos fatores geográficos mistos.

Desse modo, a Geografia executadas até então levam em consideração as questões inerentes à superfície terrestre, não privilegiando as interações sociais e os jogos de circulação. As transformações no mundo, principalmente no pós-guerra, mudaram completamente a relação homem-meio, de modo a mudar também a forma de fazer geografia. Aumentos das áreas urbanas e industrializadas, desenvolvimento constante no que tange a técnica/tecnologia e a comunicação, diversidade e diferenças social, distanciamento cada vez maior com a natureza, tudo isso levou aos geógrafos a perceber que era necessário um aprofundamento maior de suas análises (mudança metodológica), já que as que estavam postas não davam conta de responder aos problemas existentes (CLAVAL, 2014).

Diante desse cenário, começa-se a buscar uma renovação metodológica, uma nova maneira de fazer Geografia, dando-lhe uma nova perspectiva. A solução encontrada foi a tecnificação dos procedimentos, fazendo uso principalmente da matemática e da estatística como perspectiva de conferir a geografia uma linguagem mais empirista (CLAVAL, 2014).

Inseridos em uma realidade urbana, com uma forte circulação, redes e complexos, além do 
avanço tecnológico, leva a geografia à para estudar as relações sociais, onde o meio não mais ditava as regras. A chamada Nova Geografia preocupou-se com a criação de leis e modelos, validados por procedimentos estatísticos, influenciados pelas ideias sistêmicas, onde a concepção é entender os fatos geográficos considerando a sua a dinâmica, isto é, não apenas identificar os componentes, mas sim, a conexão existente entre eles com o propósito de compreender seu funcionamento (SOTCHAVA, 1977; CLAVAL, 2014).

Christaller (1966), voltado para os estudos da dinâmica urbana, atentava para o fato de que o desenvolvimento de determinadas configurações espaciais não acontece por acaso, mas sim, por apresentar padrões e regularidades, compondo uma hierarquia nos processos que poderiam ser entendidos tendo por base dados estatísticos e considerando/observando as questões econômicas e sociológicas. Para o autor, as condições geográficas não impunham limites ao desenvolvimento das cidades, sendo essas relacionadas diretamente as ideias de limite crítico da demanda e alcance médio de serviço. Esses dois conceitos ajudam a entender o porquê da centralidade que certas cidades exerciam sobre outras.

Também influenciado pelas concepções sistêmicas, Sotchava (1977) faz uso do conceito de geossistema como aquele voltado para os estudos da chamada Geografia física, isto porque o foco do geossistema seria analisar as questões refrentes aos fenômenos naturais, no qual os fatores sociais atuam como influenciadores na sua estrutura.

A análise dos geossitema parte da premissa de considerar o estado primitivo dos fenômenos, ou seja, como eles deveriam ser caso não houvesse perturbações, na maioria das vezes ocasionado pela ação humana, na sua dinâmica natural para a partir disso reconhecer quais foram as forças de distúrbios que atuam sobre determinado sistema provocando mudanças. Sendo assim, as paisagens atuais nada mais são do que paisagens primitivas que foram modificadas pela ação do homem sobre ela, o que concerne a paisagem a ideia de dinamicidade (SOTCHAVA, 1977).

Sotchava (1977) conceitua o geossitema como sistema aberto, isto é, capaz de trocar matéria e energia de forma hierárquica, constituindo unidades espaciais (partes) que dialogam e a fim de manter o funcionamento do sistema por meio de uma organização espacial, no qual cada uma dessas unidades são independentes umas das outras, mas que estão em constante relação.

Diante disso, parte da premissa de entender quais seriam as condições normais de funcionamento dos sistemas, tem-se a possibilidade de criar leis e modelos que permitem a ação mais pontual tendo em vista o planejamento com foco no desenvolvimento socioeconômico.

O que levou a Nova Geografia receber críticas está no fato da mesma fazer uso exarcebado da técnica, levando-a a preocupar-se apenas com os resultados. $O$ pouco interesse no aprofundamento teórico caracterizou a técnica como vazia isto por que, faltava-lhe a reflexão sobre o que estava embutida nos dados, não havia a perspectiva de mudar a realidade social. Era a ciência pela ciência. Os jogos de interesses que estavam por trás das ações não eram contemplados nas análises (CLAVAL, 2014).

Após os eventos da Segunda Guerra Mundial, o mundo passa por transformações que repercutiram não apenas na configuração do espaço geográfico, mas também, na dinâmica social. Vivia-se um período de crises políticas, sociais e ambientais. A aliança da ciência e da técnica fez com que os processos de apropriação/transformação do espaço ocorram de forma mais intensa com intuito de satisfazer as necessidades do processo produtivo que ao fim só beneficia os detentores do poder (SANTOS, 2008).

Considerando a realidade posta, vê-se que estabelecer leis e modelos contribuiu para que a Geografia venha mostrar como o mundo funcionava, mas isso não era suficiente para transformá-lo, como por exemplo, a diminuição das diferenças sociais, e do por que dessas discrepâncias. Surge a necessidade de estudar as especificidades dos lugares, do jogo de poderes feitas por homens construídos socialmente, perceber a paisagem não apenas como aquilo que é 
visível, mas que também foi formado de acordo com as necessidades humanas (SANTOS, 2008; CLAVAL, 2014).

De acordo com Santos (2008) a Geografia, enquanto uma ciência humana começa a ter destaque, pois se preocupa com os estudos do espaço geográfico, bem como com a sua dinâmica. A corrente crítica da Geografia surge no auge das crises ambientais e do Chamado Marxismo Filosófico, no qual levou a questionamentos sobre as consequências do uso demasiado dos bens naturais advindos da melhoria da técnica e do avanço do capitalismo e a necessidade de entender os fenômenos espaciais por uma visão interdisciplinar. (CLAVAL, 2014).

O espaço é visto como uma totalidade no qual, para analisá-lo é necessário buscar conhecer suas partes a partir das suas relações, sendo que cada qual executa uma função para construir o todo de forma concreta. A sociedade e a natureza são um dos elementos que constitui o espaço geográfico, que apresentam valor estando este atribuído a um contexto que variam no tempoespaço. Logo, o papel da geografia não seria de servir de instrumento aos processos produtivos, mas ser crítica em suas análises e ter uma visão holística da realidade, isto é, conhecer as partes que constituem e sua interação a fim de compreender a função que cada uma executa e como ela repercute no funcionamento do sistema maior, pois o mundo é um conjunto de lugares que estão interligados. (SANTOS, 2004; 2008; 2014).

\section{PAISAGEM GEOGRÁFICA}

Desde a Antiguidade, não ainda com essa denominação, a Geografia foi conceituada como uma das responsáveis pela criação de uma imagem do mundo e por sua descrição. $\mathrm{O}$ que leva a perceber que o estudo das paisagens está intimamente relacionado com o desenvolver a história da Geografia (VITTE, 2007a; CAMPOS, 2014).

De acordo com Santos (2008) em 1925, Carl Sauer identifica que a ação humana sobre o meio também produz efeitos sobre a fisionomia das paisagens, existindo dessa maneira dois tipos de paisagem: a natural e a artificial, onde a paisagem natural é aquela que não foi alterada pela ação humana e a artificial, sendo aquela que teve interferência do homem.

A paisagem no entendimento de C. Sauer considera que os fatores sociais e naturais refletem no espaço tendo como resultado uma configuração que lhe é própria, apresentando significados diferenciados de acordo com o tempo. Porém, na análise da paisagem proposta por Sauer não é clara a interação direta entre as paisagens ditas naturais e as culturais (GUERRA e MARÇAL, 2010).

Para isso, Cavalcanti (2014) afirma que por mais que uma paisagem seja identificada como sendo uma paisagem natural, ela vai apresentar elementos culturais, isso porque, a atividade humana consegue lançar sua influência por todo o globo. Do mesmo modo que é difícil afirmar a existência de uma paisagem cultural na sua totalidade, isso por que, apesar das interferências e modificações feitas pelo homem no ambiente, essas transformações não anulam a existência dos elementos naturais, como: clima, relevo, biota, geologia.

Com o advento das teorias sistêmicas, cresce a necessidade de se buscar avaliar as paisagens também de forma integrada, deixado para trás seu aspecto meramente descritivo e se preocupando com as trocas de matérias e energias dentro do sistema, abordando o complexo físico-químico e biótico (GUERRA e MARÇAL, 2010), sendo geradas abordagens específicas para a análise ambiental e da geociência.

Surge, então, no final do século XIX a Ecologia que tem por objetivo estudar as relações dos seres vivos entre si e com o ambiente no qual estão inseridos, trazendo consigo o Ecossistema, 
conceito esse baseado em preceitos sistêmicos, com foco nos organismos bilógicos, onde se busca compreender o funcionamento dos sistemas ecológicos, a partir das trocas de energia e matéria entre os componentes bióticos e abióticos (RODRIGUEZ e SILVA, 2002).

Já em 1939, segundo Turner (1989) apud Marques e Galo (2009), apresentou-se a ideia da Ecologia da Paisagem, desenvolvida por Carl Troll, como sendo uma subcategoria da Ecologia onde o foco seria a interação entre os modelos espaciais e as interações entre os padrões e processos ecológicos. Sendo assim, a Ecologia da Paisagem seria a síntese da Geografia com a Ecologia.

Apesar do conceito de Ecologia da Paisagem ser de grande valia para o entendimento da interação e transformações ocorridas na paisagem, esta se pauta, sobretudo, no estudo das relações e processos dando ênfase ao fator biológico. Diante disso, surgi a Geoecologia das Paisagens que toma por base o conceito de Ecossistemas. Entretanto, o foco da Geoecologia não se limita a apenas aos fatores bióticos, mas também considera os elementos abióticos influenciadores na formação das paisagens (VICENTE e PEREZ FILHO, 2003).

Sendo assim, a Geoecologia como sendo disciplina prima pela análise da funcionalidade da paisagem, ou seja, não se busca estudar apenas os elementos que compõe as paisagens, mas sim quais os tipos de relação existentes dentro do sistema, como também a sua relação com outros sistemas, por exemplo, dos sistemas sociais e culturais. Nesse aspecto, a Geoecologia da paisagem procura fazer a interação com os sistemas sociais, para formar o meio ambiente global, ou seja, os sistemas ambientais e que mais tarde irão influenciar nos estudos geossistêmicos. (RODRIGUEZ e SILVA, 2002).

De acordo com Bertrand (1972) a paisagem, portanto, não pode ser analisada de forma fragmentada, separando suas partes, pois os elementos que a compõe estão em uma continua e permanente interação. $\mathrm{O}$ autor propõe que os estudos da paisagem partam do princípio de classificá-las em unidades homogêneas, no qual cada unidade seja reflexo de uma complexa interação dos atributos (físicos e antrópicos) responsáveis pela sua dinâmica.

$\mathrm{O}$ conceito de Unidade de Paisagem pode ser entendido como sendo aquelas áreas que se constituem por certo grau de homogeneidade resultado da relação das características ecológicas de um determinado recorte espacial com as atividades antrópicas que nela se realizam. Apesar da grande complexidade de delimitar a Unidade de Paisagem, visto a quantidade de componentes que podem ser considerados (fatores naturais e antrópicos) ela se torna interessante já que permite que se tenha uma visão mais ampla da dinâmica da paisagem, como também permite identificar as áreas mais frágeis de cada unidade o que pode auxiliar no processo de gestão das mesmas (AMORIM e OLIVEIRA, 2008).

As delimitações das unidades da paisagem, por fim, ajudam a identificar quais porções do território apresentam fragilidades ambientais ou potencialidades de uso isso contribui de forma demasiada na gestão do território como forma de pensar em alternativas para o melhor aproveitamento dos recursos naturais.

\section{CONSIDERAÇÕES FINAIS}

O conhecimento geográfico é bastante antigo associado, principalmente a uma leitura espacial que possibilitou o desenvolvimento das atividades humanas. A geografia enquanto ciência passou por inúmeras modificações na sua maneira de fazer a geografia que acompanharam as transformações que ocorreram na sociedade e na sua forma de relacionar e ver e intervir na natureza, resultando em um grande mosaico de paisagens geográficas.

Todavia, vale salientar que essas intervenções das ações humanas oriundas do desenvolvimento da técnica e que se acentua desde as Revoluções Industriais, levaram a modificações no 
equilíbrio dinâmico da natureza e que, consequentemente, reverberam de maneira negativa sobre a sociedade, atingindo de forma mais intensa, principalmente, as classes menos favorecidas de qualidade ambiental, social e econômica.

Cabe a geografia, como sendo a ciência que estuda o espaço geográfico, compreender o seu movimento de construção no decorrer do tempo-espaço por meio do diálogo entre a sociedade e natureza que podem ser visualizadas na paisagem.

A paisagem é, portanto, resultado da inter-relação dos fatores físicos e humanos em uma dada porção do espaço de modo a criar áreas que apresentam características especificas que se distinguem das outras, as chamadas unidades de paisagem pelo seu grau de homogeneidade que ao serem visualizadas no todo, mostram a paisagem como sendo um todo heterogêneo e dinâmico.

A paisagem como categoria de análise contribui para o entendimento dos processos que atuaram e/ou atuam para definir determinada configuração espacial, necessário para pensar em uma maneira de otimizar o uso dos recursos e assim buscar a qualidade socioambiental.

\section{REFERÊNCIAS}

AMORIM, R. R.; OLIVEIRA, R. C. de. As unidades de paisagem como uma categoria de análise geográfica: o exemplo do município de São Vicente-SP. Sociedade \& Natureza, Uberlândia, 20 (2): 177198, DEZ. 2008.

BERTRAND, G. Paisagem e geografia física global. Caderno de Ciências da Terra. Instituto de Geografia da Universidade de São Paulo, n. 13, 1972.. RA`E GA, Curitiba, n. 8, p. 141-152, 2004.

CAMPOS, R. R.de. Visão de Vidal de La Blache a respeito de Friedrich Ratzel. Sociedade. e Natureza.Uberlândia, 26 (3):, set-dez.2014. p.419-432.

CASTRO, R. L. Espaço: um conceito-chave da Geografia. In: CORRÊA, R.L; CASTRO, I.; GOMES, P.C.C. Geografia: Conceitos e Temas. Rio de Janeiro: Bertrand Brasil, 1995. p. 15-49

CAVALCANTI, L de S. Cartografia das Paisagens: fundamentos. São Paulo: Oficina de Textos, 2014. p 95.

CHRISTALLER, Walter. Central places in Southern Germany. New Jersey: Prentice-Hall, 1966.

CLAVAL, P. Epistemologia da Geografia. 2 ed. ver.-Florianópolis: Ed.da UFSC, 2014. p. 255-319.

DEMO, Pedro. "Demarcação Cientifica". In: Metodologia cientifica em ciências sociais ." São Paulo: Atlas, 1995; pp. 16 - 40.

GUERRA, A. J. T; MARÇAL, M. dos S. Geomorfologia ambiental. $3^{\text {a }}$ Ed. Rio de Janeiro: Bertrand Brasil, 2010, pp. 192.

HARTSHORNE, R. Propósitos e Natureza da Geografia. São Paulo: Hucitec/Universidade de São Paulo, 1978.

JAPIASSU, H. Introdução. In: As paixões da ciência. São Paulo: Letras e Letras, 1991, p. 7 - 17.

KUHN, T. S. A estrutura das revoluções científicas. 5. ed. São Paulo: Editora Perspectiva S.A, 1997.

LA BLACHE, P.V. de. Geografia Geral: Os Gêneros de vida na Geografia Humana. Annales de Geografhia. $\mathrm{n}^{\circ}$ 111. 1911.p, 113-130.

MARQUES, A. J.; GALO, M. de L. B. T.. Escala geográfica e escala cartográfica: distinção necessária. Bol. geogr., Maringá, v. 26/27, n. 1, p. 47-55, 2008/2009

MOREIRA, R. Geografia e práxis: a presença do espaço na teoria e na prática geográfica.-São Paulo: Contexto, 2012 p. 15-46.

O pensamento geográfico brasileiro, vol 1: as matrizes clássicas originárias-2 ed. $3^{\mathrm{a}}$ reimp.- São Paulo: Contexto, 2015, p.13-37. 
RATZEL, F. O solo, a Sociedade e o Estado. R. Revista do Departamento de Geografia; n. ${ }^{\circ} 2$ FFLCH/USP, 1983. (Publicada em 1986)

RODRIGUEZ, J. M. M.; SILVA, E. V. da. A Classificação das Paisagens a partir de uma visão Geossistêmica. Mercator - Revista de Geografia da UFC, ano 01, número 01, 2002.

SANTOS, M. A natureza do Espaço: Técnica e tempo, razão e emoção. $4^{\mathrm{a}}$ Ed. $2^{\mathrm{a}}$ reimpr. - São Paulo: Editora da Universidade de São Paulo. 2004.

Espaço e Método. 5 ed., 2 reimp.-São Paulo: Editora da Universidade de São Paulo, 2014. p. 120.

Metamorfose do espaço habitado: fundamentos teóricos e metodológicos da Geografia. 6ed. São Paulo: Editora da Universidade de São Paulo, 2008, pp.127.

SOTCHAVA, V. B. O estudo dos geossistemas. Métodos em Questão. São Paulo, n. 6, 1977. 50p.

VICENTE, L. E.; PEREZ FILHO, A. Abordagem sistêmica e Geografia. Geografia, Rio Claro, v.28, n.3, 2003 p. 323-344.

VITTE, A. C. (org.) Contribuições á história e á epistemologia da geografia-- Rio de Janeiro: Bertrand Brasil, 2007a.

O desenvolvimento do conceito de Paisagem e a sua inserção na Geografia Física. Mercator Revista de Geografia da UFC, ano 06, número 11, $2007 \mathrm{~b}$. 